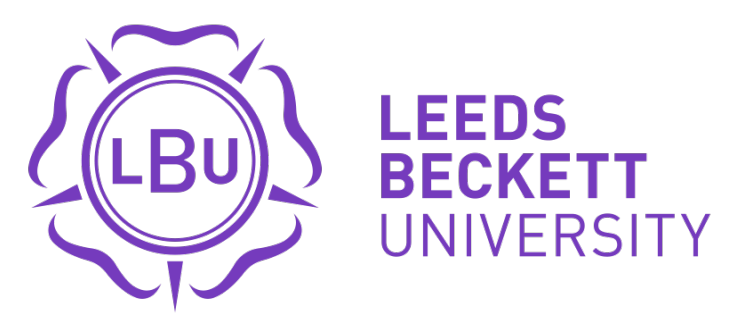

Citation:

Ewen, S (2014) Socio-technological disasters and engineering expertise in Victorian Britain: The Holmfirth and Sheffield floods of 1852 and 1864. Journal of Historical Geography, 46. 13 - 25. ISSN 0305-7488 DOI: https://doi.org/10.1016/j.jhg.2014.05.021

Link to Leeds Beckett Repository record:

https://eprints.leedsbeckett.ac.uk/id/eprint/156/

Document Version:

Article (Updated Version)

The aim of the Leeds Beckett Repository is to provide open access to our research, as required by funder policies and permitted by publishers and copyright law.

The Leeds Beckett repository holds a wide range of publications, each of which has been checked for copyright and the relevant embargo period has been applied by the Research Services team.

We operate on a standard take-down policy. If you are the author or publisher of an output and you would like it removed from the repository, please contact us and we will investigate on a case-by-case basis.

Each thesis in the repository has been cleared where necessary by the author for third party copyright. If you would like a thesis to be removed from the repository or believe there is an issue with copyright, please contact us on openaccess@leedsbeckett.ac.uk and we will investigate on a case-by-case basis. 
In the path-breaking book published in 1978, Man-Made Disasters, the sociologist Barry Turner questioned the limits to an engineer's expertise when faced with explaining the causes of socio-technological failure. Whilst engineers benefited from having technical skills with which they could account for engineering failure, they were more likely to find fault with external environmental and organisational factors that were outside their control, rather than identify deficiencies with their own specialised knowledge-base and skills-set. ${ }^{1}$ Two decades later, after Turner’s death, the book was re-issued with an additional chapter by Nicholas Pidgeon. Turner and Pidgeon established the consensus that, rather than being 'bolts from the blue', sociotechnological disasters (as ‘man-made’ disasters will be referred to in this article) are complex events, the product of long incubation periods, during which 'failures of foresight’ develop based on erroneous assumptions, misinformation or misunderstandings within large organisations. Disasters, they argued, are the outcome of a lack of knowledge, mistakes made by engineers and other interested parties, and the failure to act upon early signals of failure. They are the product of social, organisational and technical practices; they also reveal longstanding technological and administrative deficiencies within large organisations’ safety cultures. Moreover, such events are subsequently subjected to intensive scrutiny by administrative, technical and political actors, from both local and central government. ${ }^{2}$

Given the long-standing influence of Turner's work within the field of disaster studies, it is surprising that comparatively few historians have explained the causes of

${ }^{1}$ B.M. Turner, Man-Made Disasters, London, 1978, 31.

${ }^{2}$ B.A. Turner and N. Pidgeon, Man-made Disasters, Oxford 1997. See also S. Gherardi, Man-made disasters twenty years later: critical commentary, Health, Risk \& Society, 1 (1999), 233-239. 
socio-technological disasters through recourse to his classic study. The overwhelming majority of research has been published in specialised journals devoted to the study of disasters, crises and emergencies: history only really exists here as a backdrop to reveal 'a prior, more fortunate time, when foresight, prudence, good behavior or divine grace might have unscrolled history toward a happier conclusion. ${ }^{3}$ One or two exceptions exist: for example, E. L. Quarantelli, Patrick Lagadec and Arjen Boin have shown how historical studies reveal changing social interpretations of disaster, as well as cultural differences in coping with everyday disaster, but they remain concerned with explaining the emergence of systematic disaster research as a recent phenomenon. $^{4}$

This historiographical blindness to Turner is largely reflected by the historical field's focus on post-disaster reconstruction and re-planning. ${ }^{5}$ It is also the product of an eclectic and varied global interest in disasters from multiple sub-fields: urban and environmental history, the history of technology, science, technology and society

\footnotetext{
${ }^{3}$ S. Jasanoff, Introduction: learning from disaster, in S. Jasanoff, ed, Learning from Disaster: Risk Management After Bhopal, Philadelphia, 1994, 1.

${ }^{4}$ E.L. Quarantelli, P. Lagadec and A. Boin, A heuristic approach to future disasters and crises: new, old and in-between types, in H. Rodríguez, E.L. Quarantelli and R.R. Dynes, eds., Handbook of Disaster Research, London, 2007, 16-41.

${ }^{5}$ For example, L.J. Vale and T.J. Campanella, eds, The Resilient City: How Modern Cities Recover from Disaster, Oxford, 2005; G. Parrinello, The city-territory: largescale planning and development policies in the aftermath of the Belice Valley Earthquake (Sicily, 1968), Planning Perspectives 28 (2013), 571-593.
} 
studies, planning history, and, more recently, cultural history. ${ }^{6}$ Whilst one can celebrate the multi-disciplinarity of the field, the history of disasters lacks a disciplinary centre, which has inevitably generated a fragmented approach towards historical analysis.

In nineteenth-century Britain, civil engineering was an evolving field of technical knowledge and professional practice contingent on the diffusion of shared cultural beliefs through an associational network. Engineering knowledge evolved through practice, which included learning from mistakes made on the ground. The only really effective way that such knowledge could be shared more widely was through national associations of professionals, such as the Institute of Civil Engineers (ICE), founded in 1818, and the Institution of Mechanical Engineers (IME), established in 1847, which organised lectures and published proceedings for wider dissemination. With increasing specialisation, new fields emerged, each with their

\footnotetext{
${ }^{6}$ On the relationship between these sub-fields, see J.K. Stine and J.A. Tarr, At the intersection of histories: technology and the environment, Technology and Culture, 39 (1998), 601-640. For a flavour of the recent literature, see C. Mauch and C. Pfister, eds, Natural Disasters, Cultural Responses: Case Studies toward a Global Environmental History, Lanham, 2009; G. Bankoff, U. Lübken and J. Sand, eds., Flammable Cities: Urban Conflagration and the Making of the Modern World, Madison, 2012; J.H. Jackson, Paris Under Water: How the City of Light Survived the Great Flood of 1910, New York, 2010; S. G. Knowles, The Disaster Experts: Mastering Risk in Modern America, Philadelphia, 2011.
} 
own knowledge, approaches and institutions, which inevitably meant that the profession lacked a single coherent voice. $^{7}$

Nowhere was the quest for professional expertise more evident than in the field of nineteenth-century British waterworks design. In their pursuit of ever larger supplies of potable water, private companies and municipal authorities extended their urban footprints ever further into the surrounding countryside. Public health crises, marked by outbreaks of cholera and other water-borne diseases, were an inevitable consequence of the unprecedented growth of industrial towns during the first-half of the nineteenth century. Waterworks were consequently built to provide a regular supply of clean water for commercial, industrial and residential consumers. Moreover, since the provision and management of waterworks was integral to the successful functioning of the urban economy, the supply of water had to be regulated and serviced by large organisations. These included joint-stock companies, quasi-elected property-owning oligarchies, and a small but growing number of elected municipal water departments, all of which drew upon an increasingly specialised external labour pool to design the plans and engineer the works. ${ }^{8}$

\footnotetext{
${ }^{7}$ R.A. Buchanan, Institutional proliferation in the British engineering profession, 1847-1914, Economic History Review 38 (1985), 42-60.

${ }^{8} \mathrm{~J}$. Hassan, The growth and impact of the British water industry in the nineteenth century, Economic History Review 38 (1985), 531-547; R. Millward, Private and Public Enterprise in Europe: Energy, Telecommunications and Transport, 1830-1990, Cambridge, 2005, 33-58; H.L. Platt, Shock Cities: The Environmental Transformation and Reform of Manchester and Chicago, Chicago, 2005; H. Ritvo, The Dawn of Green: Manchester, Thirlmere and Modern Environmentalism, Chicago, 2009; J. Broich, Engineering the empire: British water supply systems and colonial societies,
} 
This paper is the first to integrate the historical scholarship on Victorian urban water supplies with the sociology of disasters, in order to scrutinise the ways that socio-technological disasters challenge existing professional expertise and culture. It continues a well-established trend in the history of technology literature to assess the value of technological change through detailed empirical analysis. ${ }^{9}$ Two major reservoir failures in mid-nineteenth-century urban-industrial Britain - the Bilberry Reservoir above Holmfirth, near Huddersfield, in West Yorkshire (1852), and the Dale Dyke Reservoir at Low Bradfield, up-river from Sheffield in South Yorkshire (1864) - involving high human casualties, brought the engineering profession into dispute in explaining systemic failures in waterworks technology. Engineers debated whether such events were the product of poor engineering, defective management or natural causes. Evolving knowledge formed the bedrock for such contestations, which took place in various professional and public arenas. By focusing on the relationships between different experts during these two cases, this paper argues that the creation and dissemination of expertise occurred on contested terrain. It draws upon extensive archival research into the records of the waterworks' proprietors, local and central government, as well as the media. In so doing, it contributes to growing scholarly interest in the history of professional experts as members of an elite group responsible for the control and management of the environment and its resources.

1850-1900, Journal of British Studies 46 (2007), 346-365; J. Thornton and P. Pearson, Bristol Water Works Company: a study of nineteenth-century resistance to local authority purchase attempts, Water History 5 (2013), 307-330.

${ }^{9}$ D. Edgerton, Innovation, technology, or history: what is the historiography of technology about? Technology and Culture 51 (2010), 680-697. 


\section{A tale of two floods}

The Holmfirth and Sheffield floods occurred twelve years and roughly twenty miles apart, but they shared important similarities in their design, construction and operation, as well as the public's reaction to their failure. Both involved the collapse of commercially-designed and legally-sanctioned earthfill embankment reservoirs, which remained a popular style of reservoir construction into the second-half of the nineteenth century despite growing safety concerns. Although they were subject to cracking and subsidence, they remained popular on grounds of cost and because they constituted an agreed type of ‘working knowledge’ following years of practice. As John Pickstone has shown, technological and scientific decision-making was invariably based on available knowledge, which was derived from a combination of observational and interventional methods: since the latter was, in the mid nineteenth century, an expensive and risky option for contracted engineers, they preferred to follow existing methods rather than experiment with alternative building materials like concrete and stone. ${ }^{10}$

As Christopher Hamlin and Anthony Wohl have shown in relation to Victorian public health improvements, local elites invariably based their decisions about infrastructural investment on a combination of incomplete and evolving technical knowledge, weighed down by the financial burden imposed by rate-payers,

${ }^{10}$ N. Smith, A History of Dams, London, 1971, 171-181, 212-225; J.V. Pickstone, Working knowledges before and after circa 1800: practices and disciplines in the history of science, technology and medicine, Isis, 98 (2007), 489-516; J.V. Pickstone, A brief introduction to ways of knowing and ways of working, History of Science, 49 (2011), 235-245. 
which inevitably meant that the less risky option was usually opted for. ${ }^{11}$ Technological decision-making was similarly constrained by evolving scientific knowledge about bacteriology and disease prevention: for instance, studies by Hamlin and Werner Troesken have traced changes to knowledge about the harmful environmental effects of lead pipes in local water systems during the late nineteenth century. Sheffield was a notable case of a city suffering from an epidemic of leadpoisoning in the 1880s and 1890s; despite the availability of fairly conclusive evidence, however, its political leaders were 'not certain that the lead poisoning was really due to the water. ${ }^{, 12}$ Commercial organisations such as waterworks companies were also constrained by the available knowledge at their disposal. ${ }^{13}$ Thus, the immediate relevance of Turner's model is discernible; the adherence to an inherently defective method of construction was the product of evolving specialist engineering knowledge. It also reflected the centrality of financial factors to an organisation’s safety culture during a period of heavy capital investment, a point similarly noted by

${ }^{11}$ C. Hamlin, Muddling in Bumbledom: local governments and large sanitary improvements: the case of four British towns, 1855-85, Victorian Studies 32 (1988), 55-83; A.S. Wohl, Endangered Lives: Public Health in Victorian Britain, London, 1983.

${ }^{12}$ C. Hamlin, Bacteriology as a cultural system: analysis and its discontents, History of Science 49 (2011), 269-298; W. Troesken, The Great Lead Water Pipe Disaster, Cambridge, MA, 2006, quote at 162.

${ }^{13}$ Thornton and Pearson, Bristol Water Works, 311-314; J. Hillier, Implementation without control: the role of the private water companies in establishing constant water in nineteenth century London, Urban History 41 (2014 forthcoming). 
Eda Kranakis in her study of organisational failures leading up to the collapse of the Quebec Bridge in 1907. ${ }^{14}$

Bilberry Reservoir was constructed in the Holme Valley in West Yorkshire, approximately ten miles south of the textiles town of Huddersfield, roughly thirty miles south-west of Leeds, and three miles south-west of and above Holmfirth, a small cloth town of around 5,000 inhabitants. Holmfirth was situated at the bottom of the valley at the confluence of the Holme and Ribbleden rivulets, and was described by White's Directory as a growing town with a thriving associational culture built around the local mechanics’ institute. ${ }^{15}$ Dale Dyke Reservoir was built in the Loxley Valley, some eight miles north-west of the thriving steel town of Sheffield in South Yorkshire and above the manufacturing village of Low Bradfield with its waterpowered industries. ${ }^{16}$ Both reservoirs specifically provided water for commercial customers: the former supplied the water mills located along the River Holme; the latter offered compensation water to the cloth mills situated along the river Loxley in anticipation of further reservoirs being constructed in the valley to supply Sheffield's rapidly growing population.

The Bilberry Reservoir was to be one of three service reservoirs constructed by the HRC, which was, by an 1837 Act, constituted by a group of millowners and

\footnotetext{
${ }^{14}$ E. Kranakis, Fixing the blame: organizational culture and the Quebec Bridge collapse, Technology and Culture, 45 (2004), 496-499.

${ }^{15}$ William White's Directory of Leeds, Bradford, Huddersfield, Halifax, Wakefield, Dewsbury \&c., $11^{\text {th }}$ edn, Sheffield, 1866, 394-395.

${ }^{16}$ G. Amey, The Collapse of the Dale Dyke Dam 1864, London, 1974, 3-13; D. Smith, Conflict and Compromise: Class Formation in English Society 1830-1914, London,
} 1982. 
other property-owners. ${ }^{17}$ Dale Dyke Reservoir was the venture of the SWWC, which had been incorporated in 1830 to supply water for commercial and domestic purposes by tapping the springs and rivers in the neighbouring Redmires and Rivelin valleys. Its directors and shareholders were largely drawn from the town's elite, or were major landowners across South Yorkshire; similarly, the HRC was dominated by millowners and manufacturers in the immediate vicinity of the town. The Loxley valley was added to the SWWC's portfolio in 1853, by an Act with powers to construct three new reservoirs - Dale Dyke, Strines and Agden - along with connecting aqueducts and tunnels to transport the water into town. ${ }^{18}$ Both ventures were ambitious for their time and illustrate how water from the northern uplands was seen in terms of its serviceability, as a resource to be collected, impounded, distributed and sold to thirsty urban populations who relied upon it for energy and nutrients. ${ }^{19}$

\section{INSERT FIGS 1 AND 2 HERE}

Both floods were major events across the Yorkshire region, as well as nationwide. The Bilberry flood was, argues Harold Platt, 'the first human-made 'natural' disaster in the modern era to achieve the status of a national tragedy,' whilst

${ }^{17}$ West Yorkshire Archives, Kirklees [hereafter WYAK] KC6/1/4, Holme Reservoir Order Book, minutes of general meeting, 3rd July 1837; Huddersfield Local Studies Library [hereafter HLSL] [unreferenced], Holme Reservoirs Act, 1837: 7 Gulielmi iv, cap. liv.

${ }^{18}$ Sheffield City Archives [hereafter SCA] YWA/2/48, Sheffield Waterworks Acts 1830, 11 Geo. IV, and 1853, 16 Vict., cap. xxii, sec.82.

${ }^{19}$ See also Ritvo, Dawn of Green, 5. 
James Winter describes the Dale Dyke's failure as 'the greatest single 'natural' catastrophe of the century' in Britain. ${ }^{20}$ They therefore illustrate the interdependence of human and natural forces in producing what Christian Pfister has recently called 'nature-induced disasters'. ${ }^{21}$ They attracted intense media scrutiny from newspapers and periodicals, and evoked considerable public sympathy through organised relief efforts by charitable groups, local government and wealthy individuals across the country. Paintings, poems and stories were produced to raise money for the relief effort, whilst organised excursions - by road to Holmfirth and by rail to Sheffield were put on to satiate the public's morbid fascination with death and destruction. ${ }^{22}$

\footnotetext{
${ }^{20}$ Notwithstanding its devastating impact, the Dale Dyke flood is not widely remembered outside of South Yorkshire, as highlighted by recent media coverage of events to commemorate the $150^{\text {th }}$ anniversary of the disaster. See, for example, O. Wright, The forgotten flood: Sheffield's tragic past remembered, BBC News Online, http://www.bbc.co.uk/news/uk-england-south-yorkshire-26478728, last accessed 13
} March 2014.

${ }^{21}$ Platt, Shock Cities, 197; J. Winter, Secure from Rash Assault: Sustaining the Victorian Environment, Berkeley, 1999, 173; C. Pfister, Learning from natureinduced disasters: theoretical considerations and case studies from Western Europe, in Mauch and Pfister, eds, Natural Disasters, Cultural Responses, 18.

${ }^{22}$ WYAK T/H/F/79, Anon, Lines on the Holmfirth Flood, occasioned by the bursting of the Bilberry Dam, February 5, 1852, Sheffield, 1852; C. Robinson, Holmfirth Flood. Poems on those that were drowned; and on the hair-breadth escapes, Holmfirth, 1854; S. Harrison, A Complete History of the Great Flood at Sheffield on March 11 \& 12, 1864, London and Sheffield, 1864. 
Statistically, the Sheffield flood trumped Holmfirth. Officially, 250 people drowned in Sheffield, as against 81 at Holmfirth, although a local historian has since calculated the death toll at Sheffield, including deaths through debilitating illnesses caused by deep water immersion, at $306 .{ }^{23}$ Property destruction was widespread in both cases: in Sheffield, 31 factories, mills or workshops were destroyed, 55 more were partially destroyed or damaged, and 237 were flooded; in the Holme Valley, 14 mills or dye-houses were destroyed, 22 more were seriously damaged along with 44 large shops and two iron foundries. Some 800 houses in Sheffield and the Loxley valley were destroyed or abandoned, and a further 4,357 flooded; in the Holme valley 34 houses were completely destroyed with serious damage caused to 139 more. Bridges, churches, roads and public houses were wiped out by the fast moving flood waters in both towns. ${ }^{24}$ In the immediate aftermath, unemployment was rife across both districts, but was more acutely felt in the Holme Valley, which was entirely dependent upon the mills: the Holmfirth Flood Relief Fund recorded some 4,986 adults and 2,142 children unemployed; workers also had their tools washed away. ${ }^{25}$ Yet statistics alone do not tell us much about the extent of socio-technological disasters and their wider social, cultural and political impacts, not least the limitations of expert engineering knowledge, to which this paper turns.

\footnotetext{
${ }^{23}$ K. Lightowler, Sheffield Flood: The Aftermath, Sheffield, 2007.

${ }^{24}$ SCA SY/295/C1/17, Sheffield Constabulary memorandum book, 1864-1874; WYAK T/H/F/23, Scrapbook containing lists of loss of property, lives, mills, houses, 17 February 1852.

${ }^{25}$ WYAK T/H/F/1, Holmfirth Relief Fund minute book, 9 February 1852; WYAK T/H/F/2, Resolutions of the Holmfirth Committee, 7 February 1852.
} 


\section{Engineering expertise}

The Holmfirth and Sheffield floods reveal two types of professional experts within the civil engineering profession in the mid nineteenth century. First were the internal experts; those engineers who enjoyed what Harry Collins and Robert Evans call 'interactional expertise', in that they had been commissioned by the waterworks' proprietors to design, build, supervise and manage the reservoirs that subsequently failed. These engineers derived their expertise from their interactions with working technologies on the ground; they were able to draw on their working experience as evidence of their expertise. Whilst, then, internal experts could point to their individual record as testimony of their expertise, in practice expertise was a collective form of identity located in the 'social group' of engineers with their shared language, working practices and professional status. ${ }^{26}$

The second group were the external experts; a small cadre of engineers who were instructed, either by central government or local parties, to intervene in the deliberations about the alleged causes of the engineering failure. These men enjoyed 'contributory expertise'; their knowledge was derived from their scrutiny of the sociotechnologies, but they were never intimately involved with the schemes. As such, these men were more likely to refer to their theoretical knowledge and understanding of technology, rather than draw upon their working knowledge; their interaction was more intermittent than that of the interactional expert. ${ }^{27}$ Together, the two expert groups' deliberations took place in a variety of public arenas, starting in the disaster zone itself where engineers, journalists, the coroner, and the voyeuristic public visited and observed; the devastated remains of the reservoirs were duly transformed into

\footnotetext{
${ }^{26}$ H. Collins and R. Evans, Rethinking Expertise, Chicago, 2007, 77-90.

${ }^{27}$ Collins and Evans, Rethinking Expertise, 24-25.
} 
'field sites' through which the reasons for failure could be identified and disputed. In this sense, to paraphrase Thomas Gieryn, the disaster site became a 'truth-spot' in which a variety of knowledge claims about the safety of the site were produced and challenged. ${ }^{28}$

Following on from the observations made of both reservoirs, the deliberations shifted into the coroner's court, before moving onto the town hall, boardroom and the House of Lords, where the Select Committee on Private Bills sanctioned the two organisations' respective bills to rebuild the breached dams. They were also reported at length in local and national newspapers, alongside editorial commentaries and correspondence from interested parties. Whereas the internal experts' interests were inextricably bound up with the public disputes over the explanations for the failure, which inevitably emphasised the subjectivity of their expertise, the external experts, particularly the government inspectors, were depicted as disinterested observers whose role was to objectively assess the facts of the case in order to make a balanced judgment on the causes of failure.

In both cases, there was little noteworthy criticism or questioning of the consulting engineers responsible for the two reservoirs in the lead up to the accidents. Although problems were identified during construction, the reputations of the two engineers involved - George Leather, who was responsible for Bilberry Reservoir, and his nephew, John Towlerton Leather, who designed Dale Dyke - outweighed any efforts to scrutinise their involvement in either. Both men followed a common career trajectory to nineteenth-century engineering, acquiring ‘on-the-job’ expertise, firstly, through apprenticeship and, secondly, by pursuing independent practices. George's

${ }^{28}$ T.F. Gieryn, City as truth-spot: laboratories and field-sites in urban studies, Social Studies of Science 36 (2006), 5-38. 
earlier works in bridging rivers and in designing the port of Goole for the Aire and Calder Navigation Authority brought him notoriety, and he had, since 1837, been engaged with his son, John Wignall, as consulting engineer to the Leeds Waterworks Company in West Yorkshire, an industrial town with a severe water problem owing to high mortality from cholera. ${ }^{29}$

His ability to deliver on time and delegate responsibility made George an attractive prospect to the cash-strapped HRC, which offered his firm the contract to build three reservoirs outside Holmfirth in June 1838. Indeed, the initial contract specified that the HRC would appoint a resident surveyor or overlooker to work under his supervision. Inevitably, this meant that he would 'only be required to come over now \& then as circumstances might require,' thereby minimising the costs of a threeday round-trip of over sixty miles. ${ }^{30}$ Having agreed to the role, Leather interpreted the HRC's specifications liberally, and did not even visit the site within the first two years of taking the contract; nor did he visit the works after September 1844 from whence he ceased his involvement with the works because he had taken on new projects. ${ }^{31}$ The seeds of disaster were inevitably sown through lax supervision and administrative regulation within the HRC's own organisational safety culture, which served to reinforce Leather's self-belief that he could oversee safe construction 'in abstentia'. John Towlerton Leather, the eldest son of George’s colliery-owning brother James, served his apprenticeship with his uncle before specialising in waterworks. He subsequently set up practice in Sheffield, whereupon he was appointed as managing

\footnotetext{
${ }^{29}$ G.M. Binnie, Early Victorian Water Engineers, London, 1981, 44-47.

${ }^{30}$ WYAK KC6/1/34, Notes of evidence on inquest, bundle 1: George Leather, 18 February 1852, 8.

${ }^{31}$ Binnie, Victorian Water Engineers, 52.
} 
clerk, resident agent and surveyor for the SWWC in 1830, soon adding engineer to his portfolio of titles. ${ }^{32}$ With these varied job titles, Leather was regarded as a generalist rather than a specialist by his new employers. Yet he was integral in overseeing the Company’s early watershed expansion, drawing praise from his employers for his skill in building its first reservoir. ${ }^{33}$ He also continued to act as the consulting engineer after 1839, designing the Company’s works in the mid-1840s and '50s, which were executed by his successor in residence, John Gunson. ${ }^{34}$ By this time, his energies had shifted towards railway and waterways engineering, and he was heavily involved with the River Nene improvement works during the mid-1850s and '60s while construction of Dale Dyke was underway. ${ }^{35}$ This is significant because Turner cites the importance of the changing roles of key individuals and administrative bodies as a mitigating factor in failing to identify impending disasters because it leads to a breakdown in the availability of up-to-date information. Both Leathers, in shifting their attentions to new projects in other parts of the country, inevitably contributed towards socio-technological failure because they did not have control over the construction process. There was, then, a disjuncture between the design and construction phases when it might have been expected for there to have been a stricter sharing of responsibility. ${ }^{36}$

${ }^{32}$ SCA CA6/1, Sheffield Water Works annual report 1831, 2; Binnie, Victorian Water Engineers, 256.

33 SCA CA6/1, Annual reports for 1831, 2; 1833, 2.

${ }^{34}$ SCA CA6/1, Annual reports for 1844, 2; 1848, 2; 1853, 2.

${ }^{35}$ Minutes of the Proceedings of the Institution of Civil Engineers 83 (1886), 433-436.

${ }^{36}$ Turner, Man-made Disasters, 75. 
Building on Turner's work, Charles Perrow writes that the connection between construction and operational difficulties produces 'tightly coupled' risks that offer no simple explanations for failure. Large-scale urban-industrial works like reservoirs are subject to many trivial failures that are normally the product of insufficient or incorrect information, which is subsequently rectified when the event is studied and produces a lesson. Whilst, then, the Leathers were pivotal actors in both cases, they cannot be singled out as the sole reasons for failure in either. Their diminishing involvement in the construction stage was an accepted cultural practice amongst waterworks proprietors, which partly explains the lax administrative and supervisory regulation. Perrow further explains how an organisation normally employs one engineer only to supervise the construction of a plant, whilst the contractors are trusted to 'monitor themselves'. Inevitably, then, ‘[s]hoddy construction and inadvertent errors ... are part and parcel of industrial life. ${ }^{37}$

The history of technology and environmental history literatures confirm this complexity. ${ }^{38}$ Engineers enjoyed parlous relationships with their projects: some were publicly commemorated with statues and plaques; others were rewarded for their longstanding professional service with the highest accolades available within their fields; others still were simply forgotten, written out of history, or subject to public

${ }^{37}$ C. Perrow, Normal Accidents: Living with High-Risk Technologies, $2^{\text {nd }}$ ed., Princeton, 1999, 36-37.

${ }^{38}$ For example, Dieter Schott, Urban environmental history: what lessons are there to be learnt?, Boreal Environment Research 9 (2004), 519-528. 
derision for their mistakes. ${ }^{39}$ As Perrow notes, engineers were expected to monitor themselves, which meant that they were less likely to identify or satisfactorily rectify problems, not least because they guaranteed to deliver the project on time and to budget. Moreover, both men delegated responsibility for on-site supervision: at Holmfirth this involved the overlookers, a small body of on-site officials appointed by the HRC, who kept Leather informed via his inexperienced assistant; meanwhile, at Sheffield on-site responsibility rested with Gunson, albeit via a closer relationship with the consulting engineer through direct channels of communication. ${ }^{40}$

Whilst delegation itself was not a satisfactory explanation for the failures, the absence of supervisory checks and clear channels of communication - especially at Holmfirth - meant that the engineer could pass the blame onto other parties by rejecting responsibility and, further, by claiming misinformation about on-site problems. Pidgeon and O’Leary identify the blame culture that dominates postdisaster reconstruction as a significant barrier to organisational learning; it also, as Kranakis demonstrates, allows the main political actors to sidestep divisive questions

${ }^{39}$ C. MacLeod, Heroes of Invention: Technology, Liberalism and British Identity, 1750-1914, Cambridge, 2007; W.L. Kahrl, Water and Power: The Conflict over Los Angeles’ Water Supply in the Owens Valley, Berkeley, 1982.

${ }^{40}$ WYAK KC6/1/34, Leather's evidence, 18 February 1852, 9. For a flavour of the wider interest in the Bilberry flood, including its legacy, see The Times, 16 February 1852, 6; 17 February 1852, 8; 17 August 1857, 5. The Sheffield and Rotherham Independent [hereafter Independent], 14 March 1864, 4 also cites Holmfirth in comparison to Sheffield's flood. 
about the ownership and management of major utilities. ${ }^{41}$ Thus, at the subsequent coroner's inquest on 18 November 1852, whilst George Leather publicly admitted that he had received 'repeated communications from the Overlookers that they had great difficulty in getting the Contractors to do their work according to the plans \& specifications,' he also insisted that 'It was reported to me that the puddle Trenches were cut \& footed in the manner shewn in the specifications. ${ }^{42}$ Consequently, misinformation, coupled with operational failure, became the inside experts’ default explanation because it fell outside their control and thus rendered such accidents unpreventable in engineering parlance. As Turner notes, information difficulties and 'noise' (that is, relevant information 'buried in a mass of irrelevant material') become defining factors when establishing reasons for failing to act during the incubation period. $^{43}$

The same can be said about administrative practice, another type of working knowledge recognised by urban historians, which relied on the experience and knowledge of the clerk in situ and not the engineer. ${ }^{44}$ Thus, whilst the HRC's minutes

${ }^{41}$ N. Pidgeon and M. O’Leary, Man-made disasters: why technology and organizations (sometimes) fail, Safety Science, 34 (2000), 20-21; Kranakis, Fixing the blame, 517.

${ }^{42}$ WYAK KC6/1/34, Leather’s evidence, 18 February 1852, 9.

${ }^{43}$ Turner, Man-made Disasters, 99-102.

${ }^{44}$ I. Maver, A (north) British end-view: the comparative experience of municipal employees and services in Glasgow (1800-1950), in M. Dagenais, I. Maver and P-Y. Saunier, eds, Municipal Services and Employees in the Modern City: New Historic Approaches, Aldershot, 2003, 177-199; J. Moore and R. Rodger, Who really ran the cities? Municipal knowledge and policy networks in British local government, 1832- 
provide little evidence of dissatisfaction with Leather's work, it is difficult to read too much into them prior to 1846 because significant omissions point to poor recordkeeping by the clerks. ${ }^{45}$ Resolutions went unrecorded, while committee business was recorded in an ad hoc fashion. A committee of management treated its legal responsibilities to manage the reservoirs in a lax fashion; the control of sluices, for instance, appears to have been left to those commissioners who resided closest to the reservoirs. ${ }^{46}$ In the commissioners’ order book only a single occasion is recorded when the clerk was ordered to write to Leather 'to send a competent person over to examine and measure the work now done at the Bilberry Mill Reservoir and the state of the Works there with as little delay as possible. ${ }^{47}$ There is no written evidence to prove that he did this, however, or that he received an official request to visit the works himself. In this regard, misinformation was hardly surprising given the absence of effective record-keeping.

William Jacomb, who was appointed clerk in March 1846, confirmed this administrative laxity at the coroner's inquest, noting that 'there are no minutes of proceedings made by the Committee of Mr. Leather being appointed Engineer. ${ }^{48}$ For two years before March 1840, Jacomb could find no significant entry relative to Bilberry; the construction delays and difficulties simply went unrecorded. Jacomb, a Huddersfield solicitor, was also agent to the Guardian Fire and Life Assurance

1914, in R. Roth and R. Beachy, eds, Who Ran the Cities? City Elites and Urban Power Structures in Europe and North America, 1750-1940, Aldershot, 2007, 37-70.

${ }^{45}$ WYAK KC6/1/4, Committee minutes, 3 July 1837; 30 December 1841.

${ }^{46}$ WYAK KC6/1/34 William Jacomb’s evidence, 18 February 1852, 5.

${ }^{47}$ WYAK KC6/1/4, Committee minutes, 25 March 1840.

${ }^{48}$ Jacomb’s evidence, 18 February 1852, 2. 
Company, the Family Endowment Society, and the West Riding Union Bank, and clearly understood the importance of organised record-keeping. As a well-connected member of the local social elite, Jacomb used his specialist administrative knowledge to cultivate a position of authority within the local community. His impact on the HRC's management is immediately discernible: minutes record that he held meetings in his Huddersfield offices and systematically recorded business. He was also more actively involved than his predecessors in the management of the HRC's affairs: for example, minutes record the opening of channels of communication with the millowners, ratepayers, mortgagees and engineers. ${ }^{49}$ By this stage, however, the HRC was insolvent and could not afford to carry out appropriate repairs to the leaking reservoir; Jacomb had been hired mainly to represent the body in its litigation against its creditors and mortgagees. Thus, the archival record reveals relevant details about organisational culture and practice, which contributed significantly towards failure, and is much more than an empirical record of decision and non-decision making. ${ }^{50}$

\section{Explaining 'environmental' disasters}

As we have seen, then, Turner's work on disasters ascertains how the seeds of a socio-technological disaster are sown during its incubation period, in which a series of 'ambiguous or unnoticed events' take place to alter 'the notionally normal starting point.' The environment plays a significant role in incubating a disaster, not least

${ }^{49}$ Williams's Directory of the Borough of Huddersfield, London, 1845, 32; WYAK KC6/1/4, Minutes of parliamentary committee, 21 March 1846; 7 April 1846; 14 April 1846.

${ }^{50}$ On non-decision making, see J. Garrard, Leadership and Power in Victorian Industrial Towns 1830-80, Manchester, 1983. 
because there is a discrepancy between 'the environment as it had been believed to be, and the environment as it actually is. ${ }^{, 51}$ More recently, Perrow reaffirms the role played by the environment in adding to the 'interactional complexity' of components of a socio-technical system, 'since it impinges upon many parts or units in the system. $^{, 52}$

In engineering practice, this meant that the environmental conditions that initially shaped the location of both reservoirs subsequently changed or were found to be different. As Harold Platt has shown, most knowledge about waterworks was acquired piecemeal through on-the-ground training, which included learning from mistakes: 'Unprecedented in scale, the public works project became a source of both on-the-job education in hydraulic engineering and influential advances in waterworks technology. ${ }^{53}$ Similarly, fire acts as a catalyst for changes in urban land use, building styles and materials, political regimes as well social and cultural attitudes towards risk, but this working knowledge is only ever acquired through the experience of conflagration. ${ }^{54}$ Consequently, both floods simultaneously point to incomplete exploratory research into the geological composition of the two reservoir sites, as well as evolving working knowledge about the environmental context in which they were both constructed. More popularly, environmental conditions served as useful lay explanations in a time of great uncertainty, as noted in the Sheffield and Rotherham

\footnotetext{
${ }^{51}$ Turner, Man-made Disasters, 193.

${ }^{52}$ Perrow, Normal Accidents, 75.

${ }^{53}$ Platt, Shock Cities, 205.

${ }^{54}$ See various essays in Bankoff, Lübken and Sand, eds, Flammable Cities.
} 
Independent's editorial on that town's flood: 'Water, like fire, is a good servant but a bad master. ${ }^{55}$

Environmental factors were useful explanations for both Leathers and Gunson because they served to differentiate existing professional knowledge and practice from the unanticipated factors that caused accidents. Perrow's work on complex interactions in socio-technologies, in which unexpected and unfamiliar sequences can occur, and which subsequently undermine system stability, further illustrates this point. As he writes, 'linear interactions are those in expected and familiar production or maintenance sequence, and those that are quite visible even if unplanned,' whereas complex interactions 'are those of unfamiliar sequences, or unplanned and unexpected sequences, and either not visible or not immediately comprehensible. ${ }^{56}$ Towlerton Leather and Gunson both argued that their post-disaster excavations of the Bradfield site revealed a landslip of 'some hundred years ago', which had likely undermined the puddle wall and allowed water seepage inside the embankment, thereby causing it to subside. ${ }^{57}$ They denied prior knowledge of this since the reservoir's foundations had been sunk down to the sandstone bed, revealing no insurmountable problems. This explanation subsequently became the accepted narrative, especially for the SWWC's directors who used it as justification for retaining monopoly control of Sheffield's water supply as well as to service their expansion in forthcoming years, especially during the House of Lords’ debates over their proposed 1864 Bill for compensating the victims of the flood. There were, then, unanticipated interactions between the

\footnotetext{
${ }^{55}$ Independent, 14 March 1864, 4.

${ }^{56}$ Perrow, Normal Accidents, 78.

${ }^{57}$ Independent, 24 March 1863, 3.
} 
technology and the environment that could not be blamed on their working practices, but were utilised in order to defend the organisational status quo.

This is not to say that the engineers neglected the importance of environmental factors on their works; more so that the changeability of environmental conditions rendered it impossible to maintain complete control. Indeed, they stressed to the coroner that they had taken appropriate remedial safety measures: for instance, after the initial embankment had leaked, Gunson had moved the dam's centre line further upstream and installed a bye-wash to provide an outlet for excess water following periods of heavy rainfall. ${ }^{58}$ For all their prudent risk management, they stressed that land slippages could not be fully planned out of the project because of their unpredictability. This was, Towlerton Leather insisted, a profession-wide immaturity, rather than the fault of a single engineer: 'I did all that I thought necessary to provide against danger. I know of no means of providing against danger except the pipes and bye wash ... There is a possibility of a landslip under the seat of the embankment having produced it, but that I cannot tell. ${ }^{59}$ This further illustrates how engineers had to adapt their working knowledge to changing environmental conditions, yet they were unlikely to be in a position to do this so long as they were unable to anticipate the unanticipated.

The fact is that few early reservoirs were designed with sufficient additional capacity for unforeseen heavy rainfall. Engineers based their knowledge on existing rainfall records, which were patchy and incomplete and, in the best cases, emergency flood defences only accommodated finite sources of water. ${ }^{60}$ Since knowledge about

\footnotetext{
${ }^{58}$ SCA CA436/11, Annual reports, 1859-63.

${ }^{59}$ Independent, 24 March 1863, 3.

${ }^{60}$ Platt, Shock Cities, 206.
} 
the safety of new socio-technologies like waterworks was path-dependent, it is fair to surmise that George Leather and his companions also suffered from insufficient knowledge about the fault-lines in the vicinity of the Bilberry reservoir. ${ }^{61}$ In his testimony, George hinted that, since the original plans had not considered unanticipated heavy rainfall, the embankment would never have held firm anyway. Similar experiences elsewhere, notably at Manchester's Woodhead Reservoir, which failed in 1849 owing to instability in the underlying rock, reinforced this view. The HRC never even consulted with an engineer on the actual siting of the dam; no exploratory test pits or trenches were dug. ${ }^{62}$

As various studies have shown, the professionalisation and institutionalisation of the fields of science, technology and engineering during the nineteenth century was subject to considerable experimentalism and trial-and-error before rational knowledge could be agreed. It relied upon interacting with the socio-technology, observing and recording its operation under different environmental conditions. In a sense, then, socio-technological failure offered valuable lessons to the engineering profession in the best way to prevent future accidents. Specialist technical knowledge was also, as Roy Macleod and John Pickstone have shown, subject to administrative and

${ }^{61}$ M.V. Melosi, Path dependence and urban history: is a marriage possible?, in D.

Schott, B. Luckin and G. Massard-Guilbard, Eds, Resources of the City:

Contributions to an Environmental History of Modern Europe, Aldershot, 2005, 262275.

${ }^{62}$ Platt, Shock Cities, 205-206; Binnie, Victorian Water Engineers, 50. 
bureaucratic pressure; the forces of bureaucracy and professionalism were duly welded together in their acquisition of knowledge as both a making and a doing. ${ }^{63}$

\section{Experts on experts}

Despite its merits, Turner's work has limitations, especially given the emergent interest in risk and uncertainty since the 1990s, which is also beginning to attract historical scrutiny. ${ }^{64}$ In particular, he underplays the language of disaster reporting and the role that this plays in a community's cultural readjustment. More recent research, however, reveals how newspapers produce a variety of emotional and cathartic discourses through their coverage of disaster, ranging from horror to grief and anger. ${ }^{65}$ Indeed, one of the ways in which specialist knowledge could be publicised more widely was through its dissemination in the popular press; only then could generalists understand the finer technological details. Expertise may serve as a

${ }^{63}$ R.H. Kargon, Science in Victorian Manchester: Enterprise and Expertise, Manchester, 1977; R. Macleod, Ed, Government and Expertise: Specialists, Administrators and Professionals, 1860-1919, Cambridge, 1988; J.V. Pickstone, Ways of Knowing: A New History of Science, Technology and Medicine, Chicago, 2001.

${ }^{64}$ For example, U. Lübken and C. Mauch, Uncertain environments: natural hazards, risk and insurance in historical perspective, Environment and History 17 (2011), 1-12. On risk, see U. Beck, Risk Society: Towards a New Modernity, London, 1992. ${ }^{65}$ M.K. Pantti and K. Wahl-Jorgensen, 'Not an Act of God': anger and citizenship in press coverage of British man-made disasters, Media, Culture, Society, 33 (2011), 108; K. Rozario, Making progress: disaster narratives and the art of optimism in modern America, in Vale and Campanella, eds, Resilient City, 27-54. 
way of distinguishing groups of individuals, but dissemination is integral to the process because it enables social and political elites, as well as the general public, to 'make decisions about who counts as an expert and who does not in ... technological disputes in the public domain. ${ }^{66}$

In these two cases, media attention was most intensive locally, but both simultaneously attracted significant national focus, especially in their relief efforts. In Sheffield, the two main newspapers were divided along party lines when reporting on the causes of failure as well as their preferred solutions. The Tory-owned Sheffield Telegraph, published daily, was vocal in its opposition to both the SWWC's attitude towards public safety and the town council’s toothless regulation, seizing the opportunity to push the agenda for the Anglican and steel manufacturing opposition on the council. Its editor, William Leng, publicly attacked the SWWC from the outset, declaring that 'The Bradfield Dam was a mistake, or if not a mistake we should like to know what it was. It was made to perform a certain duty, and it has proved itself unequal to the duty. ${ }^{67}$ Leng also reprinted articles from the professional press that were critical of the engineers, including an article from The Builder, which condemned Towlerton Leather for failing to install sluices to reduce the water level, and for his use of loose and porous materials in the puddle wall. ${ }^{68}$ The Sheffield and Rotherham Independent, another daily newspaper, distanced itself from publicly condemning the reservoir's construction or management, largely because its editor, the Liberal Robert Leader, was a member of the relief committee alongside other members of the local elite, including the mayor and town clerk.

\footnotetext{
${ }^{66}$ Collins and Evans, Rethinking Expertise, 133.

${ }^{67}$ Sheffield Daily Telegraph, 15 March 1864, 4.

${ }^{68}$ Quoted in Sheffield Daily Telegraph, 21 March 1864, 2.
} 
Holmfirth lacked its own newspaper; instead, the Chronicle, published weekly in nearby Huddersfield, provided the most systematic coverage of its flood. As a result, criticism was more muted than in Sheffield; the newspaper too refused to 'indulge in comments either pro or con' until the coroner’s inquiry had finished, preferring to 'call attention to the very proper proceedings of the Coroner, in making Sir George Grey [the Home Secretary] acquainted with the facts, and in seeking for the assistance of a Government Engineer to examine and report upon the state of the reservoir. ${ }^{69}$ Only after the coroner's verdict of negligence on the part of the HRC did it print critical commentary, publishing a lengthy letter from Thomas Pearson Crosland, one of the commissioners, who, amongst other complaints, cited the failure of the overlookers to maintain public safety:

\begin{abstract}
It was not the business of the Commissioners to go personally and see that their orders were carried out. I charge the blame on the officials, by whose culpable neglect of duty a prosperous valley has been desolated, and an amount of human life sacrificed which is truly appalling to contemplate. There are the men who ought to have been subject to the verdict of the jury, and not men who were as innocent of sacrificing the lives of the inhabitants of the valley of the Holme as the jury themselves. ${ }^{70}$
\end{abstract}

Crosland and others subsequently stressed the importance of rebuilding the broken dam for the local economy, shifting the debate away from ascribing blame onto more sympathetic issues that affected the newspaper's readers. ${ }^{71}$ Newspapers served as alternative, sometimes conflicting, spaces within which knowledge claims could be made, challenged, resisted or tempered, particularly where political points could be

\footnotetext{
${ }^{69}$ Huddersfield Chronicle, 7 February 1852, 4; 14 February 1852, 6.

${ }^{70}$ Huddersfield Chronicle, 13 March, 7.

${ }^{71}$ See, for example, further correspondence in 20 March 1852, 3.
} 
scored. They also reveal, as Turner recognised, the limitations in professional expertise, not least because engineers, with their specialised vocabulary, lacked the ability to connect with a generalist audience. ${ }^{72}$ This is significant because interactional experts depend on the support of generalists to evidence their claims to legitimacy. Thus, in failing to sustain popular support, the engineers in both cases faced public censure and de-legitimisation.

In addition to this newspaper debate, public inquests were also held in both cases, drawing in the central government through the appointment of Home Office inspectors to provide a supposedly neutral account of events. As historians have shown, the second-half of the nineteenth century witnessed the rise of the government inspector as a new expert in information collection, supervision and certification. This was part of a broader shift from laissez-faire individualism to an interventionist approach by the state; it has also been interpreted as a method of liberal governmental rule from afar. ${ }^{73}$ In the case of post-disaster investigations, the appointment of government inspectors reflects an official recognition that a line has been crossed that requires action in order to assuage public concerns about safety.

Government inspectors lacked the interactional ‘on-site’ expertise enjoyed by practising engineers, but they benefited from the bureaucratic authority that their

\footnotetext{
${ }^{72}$ Turner, Man-Made Disasters, 31.

${ }^{73}$ O. Macdonagh, The nineteenth century revolution in government: a critical reappraisal, Historical Journal 1 (1958), 52-67; T. Crook, Sanitary inspection and the public sphere in late Victorian and Edwardian Britain: a case study in liberal governance, Social History 32 (2007), 369-393; A. Woods, From practical men to scientific experts: British veterinary surgeons and the development of government scientific expertise, c.1878-1919, History of Science 51 (2013), 457-480.
} 
office-holding attached. They were, simultaneously, known to the engineers as members of the same professional networks, albeit normally as non-practising engineers. Yet they, more than any other generalist, could question the expertise and legitimacy of those whose interests were most directly affected by the events that unfolded because they understood the technology, even if they were not involved with building or managing it. As 'conscious agents of change and perpetrators of state involvement,' they influenced future policy-making in regulating such risks. ${ }^{74}$ Moreover, their appointment secured a large and interested audience through their appearance at the inquests, but also via lengthy reports in newspapers: the Independent, for example, reported that Sir Robert Rawlinson, the Home Office's Chief Engineering Inspector since 1861, was 'listened to attentively’ during his testimony following his inspection of the disaster site. ${ }^{75}$ Inspectors were lauded as belonging to a class of 'knowledgeable gentlemen amateurs', whose evidence provided assurance to the public as much as criticism of the specialists. As Macleod notes, expertise was a quality possessed by administrators, professionals, generalists and specialists. ${ }^{76}$ The acquisition and practice of expertise thus became a defining tool of government regulation during the period, and was applied locally whenever circumstances allowed it.

It would be simplistic to say that government inspectors were viewed as an unwelcome intrusion by officials keen to defend local autonomy from prying eyes. Indeed, within hours of the devastation in Holmfirth, the clerk to the Huddersfield magistrates wrote to Sir George Grey to ask for assistance in ascertaining the causes

\footnotetext{
${ }^{74}$ R. Macleod, Introduction, in Macleod, ed, Government and Expertise, 18.

${ }^{75}$ Independent, 25 March 1864, 2-4.

${ }^{76}$ Macleod, Introduction, 14, 21.
} 
of the flood. Similar letters were addressed by the clerk to the county court, the coroner and three presiding magistrates. ${ }^{77}$ Grey duly sent the Commanding Royal Engineer stationed at Newcastle-upon-Tyne, Captain Richard Clement Moody, who accompanied the magistrates on a tour of the desolated valley before giving evidence to the public inquest. ${ }^{78}$ Sheffield's town clerk and the borough coroner both wrote similar letters to Grey, now in his third term of office, the morning after their flood, again to request that 'a Government Inspector be sent down to enquire into the Cause of this dreadful Catastrophe. ${ }^{79}$ Grey again acquiesced, sending Rawlinson, accompanied by the hydrologist Nathaniel Beardmore, who represented the ICE. Their attention was particularly drawn to examine the safety of the SWWC's other works in progress. ${ }^{80}$

In both cases, the inspectors found fault with the original plans and their implementation, as well as the general management of both works. Moody censured the HRC for its 'culpable neglect', claiming that public safety might have been guaranteed 'at the cost of a few Pounds.' Its committee of management was singled out for blithely ignoring warnings about the safety of the reservoir. George Leather, too, came in for strong criticism, particularly for his lax supervision of the contractors:

\footnotetext{
${ }^{77}$ National Archives [hereafter NA] HO/45/4210, letters to Sir George Grey, 5 February 1852; 6 February 1852; 10 February 1852.

${ }^{78}$ NA HO/45/4210, Captain Moody to H. Waddington, Under-Secretary-of-State, 14 February 1852.

${ }^{79}$ NA HO/45/7656 second bundle, letters to Sir George Grey, 12 March 1864; 13 March 1864.

${ }^{80}$ NA HO/45/7656 second bundle, note by Grey, 18 March 1864.
} 
Though the immediate cause of the destruction of life and property was the neglect of the Commissioners there were faults in the 'Design' on the part of the Engineer, and great faults in the execution of that 'design., ${ }^{\prime 1}$

Rawlinson and Beardmore recorded similar faults in their investigation, finding Towlerton Leather responsible for installing insufficient capacity to run off excess water. $^{82}$ More seriously, both cases highlighted pressing concerns about the safety of neighbouring projects, themselves becoming objects for accelerated learning: Moody singled out the Holme Styes reservoir as a major cause for concern, and pressed the HRC to make urgent repairs. ${ }^{83}$ Rawlinson, meanwhile, warned that the Agden reservoir, which was under construction on the same principles as Dale Dyke, was unfit for purpose because it was 'as porous as a sieve. ${ }^{84}$

Although the Holmfirth and Sheffield floods were local events - and have subsequently become part of those towns' collective identities ${ }^{85}$ - the anxiety that

\footnotetext{
${ }^{81}$ NA HO/45/4210, Moody to Waddington, 9 March 1852, 4.

${ }^{82}$ Parliamentary Papers, Report on the Failure and Bursting of a Reservoir
} Embankment belonging to the Sheffield Waterworks Company, on the Night of Friday, $11^{\text {th }}$ March 1864; by Robert Rawlinson and Nathaniel Beardmore, Civil Engineers, 20 May 1864, Cmd. 290-I.

${ }^{83}$ NA HO/45/4210, Moody to Waddington, 9 March 1852, 6-7.

${ }^{84}$ Independent, 25 March 1864, 3.

${ }^{85}$ The recent $150^{\text {th }}$ anniversary of the Sheffield flood involved various local commemorative events including walks along the route taken by the flood waters. For a flavour of how the Sheffield flood is still remembered locally, see E.G. Draper, The Great Sheffield Flood 1864. A Collection of Lantern Slides and Accompanying Text, Sheffield, 1995; Sheffield City Library Local Studies Miscellaneous Papers 3351S: 
they generated nationwide indicates that they enjoyed a wider prominence that extended beyond the towns' devastated environs. When, for example, Manchester Corporation controversially pursued plans to dam Lake Thirlmere in the Lake District, opponents drew on the memory of both floods as a warning of the dangers associated with 'high artificial dams. ${ }^{86}$

The expertise attached to the detached inspector was, for many, a calming influence, prompting repeated requests from local MPs, officials and residents for the government to inspect other reservoirs, amidst inevitable fears about their safety. Moody subsequently visited Keighley, Huddersfield and Slaithwaite, all industrial towns in West Yorkshire, whereas Rawlinson's attention was drawn to the embankment-reservoirs built for the worsted town of Bradford. He was also approached by frightened residents from the village of Thurlstone, which was situated half-way between the devastated Bilberry and Dale Dyke works, and who understandably lived in fear of the reservoir sited above their homes at Dunford Bridge: 'this awful disaster at Sheffield has made us doubly anxious lest a similar calamity should befall us, \& ... we feel it our duty to call your attention to it in order that it may be officially examined. ${ }^{, 87}$ In the weeks following the Sheffield flood, The Heritage walks etc., Sheffield City Council and Sheffield Countryside Management, Loxley Valley Walk (n.d.). On Holmfirth: S.J. Streek, The Upper Holme Valley, Preston, 1972; G. and E. Minter, On the Trail of the Holmfirth Flood 1852, Huddersfield, 1996.

${ }^{86}$ The Times, 15 December 1877, 4.

${ }^{87}$ NA HO/45/7656 second bundle, letter from Milner and Nokes, Thurlstone, to George Grey, 23 March 1864. Rawlinson agreed that the reservoir was unsafe in his report to Grey, 18 May 1864. 
Times reported a 'natural alarm for the safety of the numerous Reservoirs which may possibly be containing and maturing the elements of similar convulsions. ${ }^{, 88}$

As news of the floods spread across the urban-industrial north, the public's interest in and fear of such disasters were given their own spatial and temporal dimensions. Prophetic safety warnings were deliberately phrased to force waterworks’ proprietors into action, as well as to prompt engineers to reconsider designs, but they equally brought public anxieties to the surface, which were political dynamite if left in inexpert hands. As Moody himself noted, tragedies like Holmfirth's had proven that:

Of all engineering works perhaps these when on a large scale demand more than any other that the design should be well considered and based on the safest principles. The most extreme care is required in carrying these designs into execution, and their subsequent management is also of the gravest importance. Faults under anyone of these heads whether from undue economy, ignorance, or neglect are certain of bringing about sooner or later the most serious results to the public. ${ }^{89}$

Only with greater attention to risk would the adjacent communities also be able to enjoy the commercial benefits to be brought by impounding the water on their doorsteps.

In addition to the government inspectors, other experienced engineers were involved in the post-disaster excavations. Worried about the Company’s likely backlash against Rawlinson and Beardmore's findings, the members of Sheffield Town Council's waterworks committee commissioned a further 'independent' inquiry from nine engineers, including such distinguished railway experts as Sir John Rennie and Charles Blacker Vignoles, as well as the pioneer of embankment-style storage

\footnotetext{
${ }^{88}$ The Times, 15 April 1864, 9.

${ }^{89}$ NA HO/45/4210, Moody to Waddington, 9 March 1852, 7-8.
} 
reservoirs, James Leslie from Edinburgh Waterworks, who similarly argued that the whole process was riddled with mistakes. Fuel was added to the fire when Rennie, past president of the ICE, advocated that important infrastructural projects like waterworks should be under municipal control:

Considering the size of Sheffield, its growing importance, the general tendency of legislation on the subject, and the reciprocal connection between water supplies and drainage and other sanitary arrangements, it is my opinion that the Corporation ought to have possession of the water works. ${ }^{90}$

Coming at a time when municipalities were branching out into the management of utilities like water and gas works, such comments were obviously intended to have political repercussions. During the 1850s and 1860s attitudes towards municipal ownership of water supplies had softened owing to longstanding fears about public health crises in industrial towns and a wider recognition that municipalities had the best interests of their residents at heart. Whereas private water companies had proven themselves useful at servicing industrial and commercial demand, as well as wealthy residential consumers, the public sector was more effective at extending service to poorer residential and commercial consumers, as well as in providing a more regular supply, including at night-time, which was important for other public services like fire-fighting. This, in turn, was advantageous for property values. ${ }^{91}$

Rennie’s comments thus bolstered the arsenal of municipalities like Sheffield, which duly began a protracted and divisive drive to seize control of the SWWC's

\footnotetext{
${ }^{90}$ SCA CA/MIN/1, Minutes of the proceedings of the Council, minutes of Water Works Company’s bill committee, 29 July 1864, xiv.

${ }^{91}$ Hassan, Growth and Impact, 531-532.
} 
works, and which finally bore fruition in 1887. As historians have shown, heightened civic consciousness, aided by a nascent enterprising spirit and growing consumer dissatisfaction with the standard of existing amenities provided by commercial suppliers, fuelled the subsequent expansion of municipal control into water supplies. Disputes over the safety of large public works such as these obviously lent ammunition to the pro-municipal lobby. ${ }^{92}$

External expertise was not, however, solely limited to those intent on finding fault with the status quo. Waterworks’ proprietors were also obliged to seek the professional judgment of outside consultants, particularly where it could be harnessed as an 'objective' defence of their existing strategies. Most significant was the appearance in both cases of the well-known civil engineer, John Frederic la Trobe Bateman. The HRC first approached Bateman in March 1846 to seek his assistance with a private bill to raise funds for fixing its leaking reservoirs. Bateman inspected their works the following month; what he reported is unknown. In March 1852, one month after the flood, he re-inspected the Holme Styes and Boshaw Whams reservoirs, and advised the commissioners on the required repairs; he then succeeded George Leather as consulting engineer, which he juggled with his ongoing work for Manchester, as well as his work for Glasgow at Loch Katrine. His professional curiosity in taking on the Holmfirth works was partially triggered by concerns about the safety of the Longdendale works, particularly after landslides in that valley caused

\footnotetext{
${ }^{92}$ M. Falkus, The development of municipal trading in the nineteenth century, Business History 19 (1977), 134-161; J. Hassan, A History of Water in Modern England and Wales, Manchester, 1998, 18-25; V. Taylor and F. Trentmann, Liquid politics: water and the politics of everyday life in the modern city, Past and Present 211 (2011), 199-241.
} 
one of his reservoirs to fail; it further illustrates how common-place it was for an engineer to accept multiple contracts, even following crises such as Holmforth's. ${ }^{93}$

The SWCC similarly consulted with Bateman during its early existence; his influence over the design plans was clearly discernible at Dale Dyke. ${ }^{94}$ In April 1864, timed to coincide with Rawlinson and Beardmore’s investigation, the Company’s directors commissioned Bateman, James Simpson (Chelsea Waterworks) and Thomas Hawksley (Nottingham Waterworks), as well as the railway embankment experts Sir John Fowler and Thomas Elliott Harrison, to investigate the Dale Dyke’s collapse. Unsurprisingly, since his attack questioned the standard model of reservoir construction, they disputed Rawlinson's findings, finding that the Sheffield engineers had taken appropriate precautionary measures, and absolving them from any blame. In their report to the directors, the engineers concluded that the accident was caused neither by engineering or design fault, but by a landslip, 'which occurred in the ground immediately on the east side of the embankment, and which extended beneath a portion of its outer slope, involving in its consequences the ruin of that portion of the bank, and producing the catastrophe which followed.' They pointed to the physical scarring of the surrounding landscape, which had been fractured across a wide area, as well as cracks and other signs of subsidence in nearby cottages, as evidence of this. ${ }^{95}$

${ }^{93}$ KC6/1/4, Minutes of parliamentary committee, 21 March 1846; 21 April 1846; Minutes of general committee, 16 March 1852. On Bateman’s work, see Platt, Shock Cities, and Ritvo, Dawn of Green.

${ }^{94}$ SCA CA/6/1, Annual report, 1850, 2.

${ }^{95}$ PP, Sheffield Reservoirs, 9-12; SCA CA/436/9, Sheffield Waterworks Bill, minutes of evidence. 
Strength in numbers worked: Towlerton Leather was exonerated from blame (though shortly thereafter replaced by Hawksley, who had supervised Nottingham's Trent waterworks for some years, as the Company's consulting engineer), while the Company maintained control over its enterprise. Despite various efforts, the Town Council did not gain control of the waterworks until 1887, after which it completed the Loxley works, which included a rebuilt and reinforced Dale Dyke. Although the Council publicly opposed the SWWC's efforts, the House of Lords' Select Committee on Private Bills believed the 'official' narrative, finding in favour of the Company's 1864 Bill to increase its water rates by twenty-five per cent in order to pay for repairs to Dale Dyke and compensate the victims. However, the Select Committee did at least add the proviso that the new lease would run for twenty-five years, which gave the Town Council sufficient time to ready itself to purchase the works. ${ }^{96}$ A similar, albeit startling, outcome at Holmfirth saw the HRC obtain sanction to draw the necessary capital to rebuild the dam from the surplus proceeds of the town's relief fund on the grounds that the community's reconstruction depended on it. The HRC was also granted permission to adjust its debts in order to enable them to maintain the works' management. ${ }^{97}$

This uneven transition to public control is unsurprising given that, as Thornton and Pearson have recently argued, 'the fact that the vast majority of local authorities successfully took control of their local water undertakings during the period should

${ }^{96}$ CA/436/9, Sheffield Water Works (Bradfield Inundation) Bill. Decision of the committee, 23 July 1864.

${ }^{97}$ WYAK T/H/F/73, Bundle correspondence, William Jacomb to Trustees of the Holmfirth Relief Fund, 1 September 1852; KC6/1/31, Holme Reservoirs Act, 1853, 16 \& 17 Vict., cap. cxxxviii. 
not be taken to mean that the process was always straightforward; multiple attempts were not uncommon and ... it is surprising that so many purchase attempts succeeded. ${ }^{98}$ It also demonstrates how slowly engineering knowledge evolved, even in the face of unanticipated accidents. Changing political attitudes towards the ownership of water utilities were, much like the prevailing laissez-faire orthodoxy of state intervention, even slower to take root. The market continued to exert a considerable influence over water policy, and this was aided and abetted by the inertia created by competing explanations of socio-technological failure.

\section{Conclusion}

The two case studies explored in this paper reveal the contestations that prevailed over the management of resources in supplying nineteenth-century urban communities with water. Knowledge about the design, construction and operation of socio-technologies like reservoirs was still largely in its infancy; knowledge was evolving with the lessons learned from each successive failure. With knowledge came expertise, which was a badge of status that was awarded to individual engineers as much as it reflected his cumulative experience. It was the product both of the piecemeal institutionalisation of professional knowledge and working practices, as well as of the cultural exchanges that occurred extraneous to these networks. An engineering family like the Leathers could still, then, be considered experts in their own field, yet derided as failures in wider cultural life. When, for example, the HRC

98 Thornton and Pearson, 'Bristol Water Works Company’, 321. The Bilberry Reservoir was rebuilt and later sold, along with the rest of the HRC's works, to Huddersfield Corporation in 1938: T.W. Woodhead, History of the Huddersfield Water Supplies, Huddersfield, 1939. 
hired an engineer to inspect the safety of its reservoirs, including the rebuilt Bilberry, during the 1870s, it kept quiet about its choice, John Wignall Leather, so as not to reopen old sores. ${ }^{99}$

Barry Turner’s work has proven useful in examining the historical incidence of socio-technological disasters. It is surprising, given its synchronic treatment of the relationship between the causality and outcome of disasters, that it has attracted such little historical interest. It reveals how such events were not 'bolts from the blue', however they may have been described by contemporaries; rather, they are the products of informational and organisational deficiencies. Moreover, by focusing on the similarities in the causes and outcomes of disasters, Turner established the value of comparative method as an important tool for disaster studies, especially in explaining the causal relationship between socio-technological systems, their wider environments and the human agents who design, build and operate them. The history of socio-technological disasters and other related crises can only really be understood from a multi-disciplinary perspective that draws on sociological explanations as much as empirical historical evidence. This paper, as well as other recent additions to the field, illustrates how integral the latter is to putting flesh on the conceptual bone. ${ }^{100}$

\footnotetext{
${ }^{99}$ WYAK KC6/1/6 Holme Reservoir order book, 19 January 1872.

${ }^{100}$ For example, J.W. Trotter and J. Fernandez, Hurricane Katrina: urban history from the eye of the storm, Journal of Urban History 35 (2009), 607-613; V. Taylor, H. Chappells, W. Medd and F. Trentmann, Drought is normal: the socio-technical evolution of drought and water demand in England and Wales, 1893-2006, Journal of Historical Geography 35 (2009), 568-591; S. Kroll-Smith and S. Brown-Jeffry, A tale of two American cities: disaster, class and citizenship in San Francisco 1906 and New Orleans 2005, Journal of Historical Sociology 26 (2013), 527-551.
} 
The combined historical and disaster studies literatures further reveal how socio-technological disasters are a consequence of the complex interaction of social, organisational and technical practices. Moreover, the role played by engineers in the occurrence of socio-technological failures, and the subsequent contestations surrounding their expertise, emerge as recurring features of post-disaster inquiry and investigation. This is discernible in the archival record, including the media, as well as public and private bodies at odds with one another. The case studies also reveal that socio-technological failures are manifested over time and are the product of incomplete and evolving knowledge and, therefore, expertise.

Historical comparative analysis of the causal factors behind sociotechnological breakdown thus reveals the commonalities in the flaws that befell design, construction and operation. The collapse of the Bilberry and Dale Dyke reservoirs reveal more similarities than differences, from the mistakes made during the design and construction stages to the engineers' defence of their working practices during the post-disaster inquiries. Both illustrate how specific 'ways of knowing' became entrenched within engineering practice and discourse; it subsequently proved difficult to challenge this agreed knowledge, especially once it had been designated and subsequently defended as a common feature of the profession's interactional expertise. The barriers to change are notoriously difficult to overcome in the face of powerful and slowly evolving information and organisational practice.

Politicians’ failures to learn from the past come as no surprise to historians, who have long lamented their blinkered contemporary focus. ${ }^{101}$ Despite recommendations from their own inspectors and public calls for greater risk awareness in the aftermath of the Holmfirth and Sheffield floods, ministers resisted

${ }^{101}$ E.H. Carr, What is History?, $3^{\text {rd }}$ edition, Basingstoke, 2002. 
calls for the central government to take on a supervisory function over reservoir safety because they feared the litigious consequences of governmental approval for projects that were later found to be defective. As Grey himself dourly warned, 'the Government cannot undertake the inspection of all such Reservoirs at the public expence. ${ }^{102}$ Instead, citing Holmfirth as a test case, the government forced all waterworks' proprietors to accept liability for losses caused by the failure of any reservoir, embankment or watercourse. ${ }^{103}$

Decades later, in 1925 when the Welsh mining village of Dolgarrog was inundated with flood waters from the privately-owned Eigiau Dam situated in the hills above, killing sixteen residents, similar questions were aired as at Holmfirth and Sheffield. Indeed, the Home Office re-examined the earlier floods in a vain attempt to finally learn from the repeated mistakes that were being made. ${ }^{104}$ After protracted soul searching and inter-departmental wrangling, the resulting legislation, the Reservoirs (Safety Provisions) Act, 1930, finally made it the legal duty of proprietors to have all large reservoirs periodically inspected by a qualified engineer before they could be certified as operational. ${ }^{105}$ By this date, the water engineers had formed their own representative institution, while the tide of municipalization had also lead to the establishment of the Institution of Municipal Engineers. For some engineers, however,

${ }^{102}$ NA HO/45/4210, Note by G.[eorge] G.[rey], 17 February 1852.

${ }^{103}$ For example, SCA YWA/2/48, Sheffield Water-Works Act, 1853, 16bVict., cap xxii, s.68.

${ }^{104}$ NA HO/45/13762 Part 1, 'Bursting of the Bradfield Reservoir at Sheffield, March 1864', 17 November 1925.

${ }^{105}$ NA HO/45/13762 Part 3, Home Office memorandum, Reservoirs (Safety Provisions) Act 1930, 6 January 1931; Municipal Review (February 1931), 44. 
the Act did not go far enough - for example, it did little to improve the condition of existing reservoirs and did not cover all reservoirs - but it did at least put the engineer at the heart of the regulation process. The engineering profession, with its advanced associational network, would continue to supervise and regulate its own activities, but it was in a far stronger position to do so. 